\title{
Nichts für Weicheier
}

Bruno Kesseli

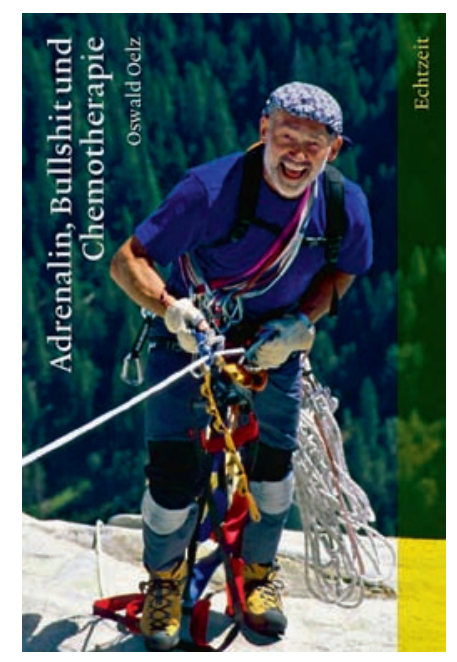

1 Oswald Oelz. Adrenalin, Bullshit und Chemotherapie. Basel: Echtzeit Verlag; 2007. 168 Seiten, gebunden, Fr. 28.- / € 19.-, ISBN 978-3-905800-07-4
Die Vitalität des Mannes auf dem Cover [1] springt den Betrachter förmlich an: Autor Oswald Oelz, passionierter Bergsteiger, Internist, Professor und ehemaliger Chefarzt Innere Medizin am Zürcher Stadtspital Triemli, hat offensichtlich eine Menge Spass am Leben. Daran kann auch die Tatsache nicht ändern, dass zum Oelzschen ABC neben Adrenalin und Chemotherapie auch ein gerüttelt Mass an Bullshit gehört, wie bereits der Titel seines Werks unzweideutig signalisiert. Die unzimperliche, aber keinesfalls unkultivierte Wortwahl ist so etwas wie ein Markenzeichen des Buchs, das aus 60 Beiträgen besteht, die der Autor für die Zeitschrift «Bilanz» verfasst hat. Um den heissen Brei herumzureden ist nicht die Sache des Oswald Oelz. Wenn er am Berg - und im übertragenen Sinn im Buch - mit dem Pickel die Eiskristalle stieben lässt, so bedeutet dies allerdings nicht, dass ihm Gehör und Gespür für die feineren Töne und Schwingungen des Lebens abgehen - schliesslich gehört auch das Stethoskop zu seiner Ausrüstung ( «Mit Eispickel und Stethoskop» lautet sinnigerweise auch der Titel eines früheren Buchs von Oelz).

Machen wir die Nagelprobe anhand des «Bullshit»-Kapitels. Wer ob dieses Rückgriffs auf die Fäkalsprache die Nase rümpft, der lasse sich von Oelz ganz nebenbei belehren, dass bereits der Moralphilosoph und Princeton-Professor Harry G. Frankfurt einen Essay zu ebendiesem Begriff - der im übrigen auch im Supplementum des «Oxford English Dictionary» enthalten sei verfasst habe. Darin werde Bullshit als Missbrauch oder Lüge definiert, die allerdings - und an dieser Stelle kommt der heilige Augustinus ins Spiel - lediglich in die Kategorie der lässlichen Sünden falle. Auch assoziativ erweist sich Oelz also als wahrer Kletterkünstler, der locker aus vermeintlichem kulturellem Tieflandmorast in lichte (Geistes-)Höhen emporsteigt.

Dort oben thront zwar auch der Friede. Vor allem aber fliesst das Adrenalin in Strömen, nicht nur im gleichnamigen Auftaktkapitel, in dem Oelz und sein Gefährte Reinhold (Messner) durch ein «Eis- und Steinschlaginferno» an der Ama Dablam hetzen, um verunglückte Kollegen zu retten. Ob er sich über Rationierung in Medizin, Arbeitszeitbeschränkungen für Assistenzärzte, Karriereplanung oder «Weicheier» Gedan-

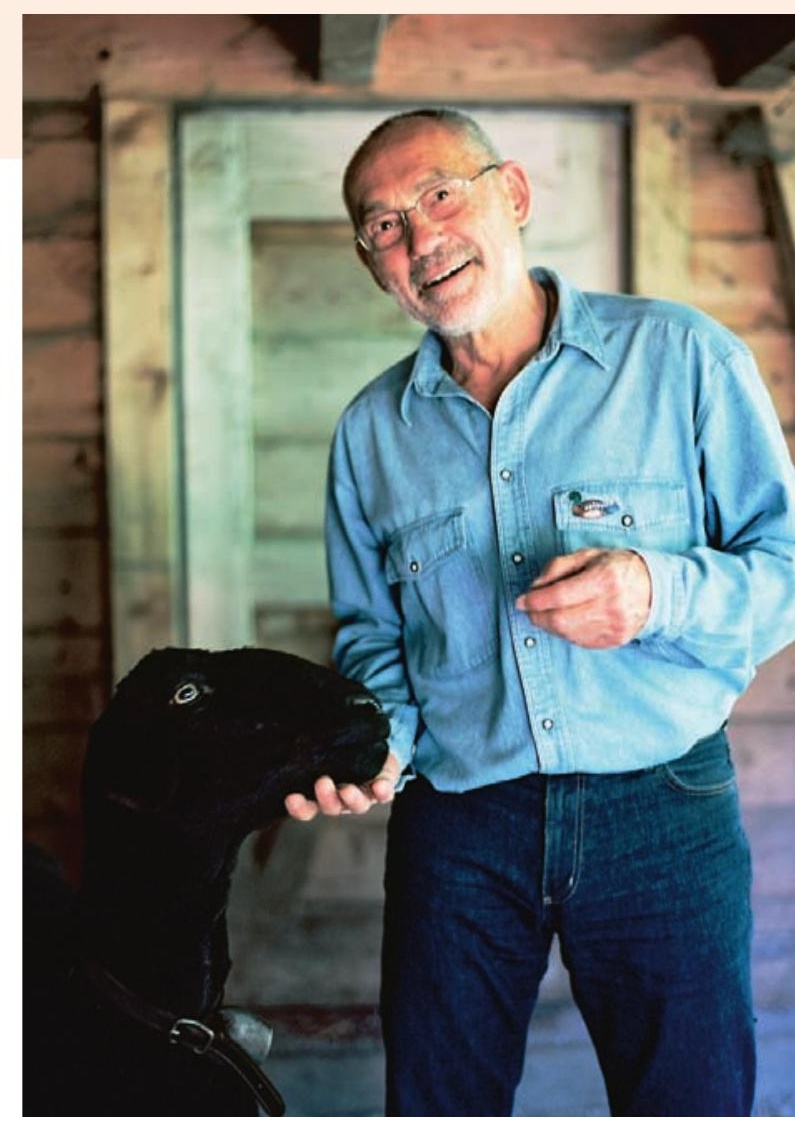

Keine Angst vor schwarzen Schafen und hohen Bergen: Oswald Oelz, Arzt und Buchautor.

ken macht: Oelz verkündet seine pointierten Ansichten weder von der Kanzel herunter noch aus einem intellektuellen Reduit heraus - sein Element ist das «volle Leben». Er ist gewissermassen die Verkörperung der im Kapitel «Karriereberatung» als Zitat der Spitzenköchin Elfie Casty formulierten Philosophie «Wenn ich Klofrau in Zürich wäre, hätte ich eben das schönste WC von Zürich.» Seine Begeisterung ist durchaus ansteckend, und da Oelz für seine spannenden Erfahrungen und mainstreamfernen Gedanken eine packende, direkte Sprache findet, haben auch diejenigen Leser einen (Lust-)Gewinn, deren mentale und physische Energie nicht dazu ausreicht, sich bei 40 Grad im Schatten einen 450 Meter hohen Felsenpfeiler im wilden Osten von Oman hinaufzuquälen.

Buchvernissage und Gespräch von Weltwoche-Chefredaktor Roger Köppel mit Oswald Oelz am Sonntag, 25. November 2007, ab 18.30 Uhr im Festsaal des Zürcher Restaurants Kaufleuten. 